\title{
Spatial dependencies in wind-related housing damage
}

\author{
Dakshina G. De Silva $\cdot$ Jamie B. Kruse $\cdot$ Yongsheng Wang
}

Received: 3 December 2007/ Accepted: 1 February 2008/Published online: 11 March 2008

(C) Springer Science+Business Media B.V. 2008

\begin{abstract}
This article examines the spatial dependence among housing losses due to tornadoes using data from the May 1999 Oklahoma City tornado. In order to examine the existence of spatial dependence and its impacts on the damage analysis, we compare an estimation based on a traditional ordinary least square model with the general spatial model. The results show that housing damage in this disaster area is highly correlated. Monetary losses not only depend on the tornado that struck residences, but are related to the damage magnitudes of neighboring houses. Average losses as well as the loss ratio increase with the Fujita Scale damage rating. We conclude that the general spatial model provides unbiased estimates compared to the ordinary least square model. In order to construct appropriate home insurance policies for tornado disasters or to improve the damage resistance capabilities of houses, it is necessary for insurance underwriters and builders to consider spatial correlation of tornado damage.
\end{abstract}

Keywords Housing damage $\cdot$ Spatial dependence $\cdot$ Tornado $\cdot$ Fujita Scale

\section{Introduction}

This study uses spatial econometric methods to examine the spatial relationship of the loss in residential market value caused by a tornado. Outside of the obvious fact that a tornado causes damage wherever it touches down, there are other reasons to believe that tornado

D. G. De Silva

Department of Economics, Texas Tech University, Lubbock, TX 79409-1014, USA

e-mail: dakshina.de-silva@ttu.edu

J. B. Kruse

Center for Natural Hazard Mitigation Research, Department of Economics,

East Carolina University, Greenville, NC 27858-4353, USA

e-mail: krusej@ecu.edu

Y. Wang $(\bowtie)$

Department of Economics, Washington and Jefferson College, Washington, PA 15301, USA

e-mail: ywang@washjeff.edu 
damage to houses may exhibit spatial dependence. Golden and Snow (1991) report that the strong wind speeds of tornadoes produce dust and debris that could be carried both near their point of origin and over great distances. The dust and debris become windborne missiles traveling at high speed that can produce collateral damage to structures in the community, in addition to the damage caused by the initial strike of a tornado. Thus, the damage to a house in a tornado disaster area may include damage due to both the tornado and the debris from other houses in the neighborhood. Houses that have brick chimneys or unsecured tile or gravel roofs may be responsible for higher secondary damage to their neighbors thus producing what we call a windborne debris effect. The debris effect is due to the damage sustained by the house either directly or indirectly. In addition to the debris effect another cause of secondary loss in market value could result from the fact that the house may now be nestled in a tract of severely damaged homes even though it may have sustained only slight damage. This negative externality exists because there is some risk to the owner or potential buyers that the surrounding houses may never be rebuilt. In addition, damage to landscape features such as mature trees may leave the area less esthetically pleasing. O'Sullivan (2003) describes the neighborhood effect as the phenomenon that when the appearance of a house is improved, the property values of neighboring houses increase accordingly thus providing a classic example of positive externality. In our study we identify both debris effect and the negative externality as the neighborhood effect. Therefore, this study extends O'Sullivan's (2003) neighborhood effect beyond the exterior appearance of houses and shows that neighboring houses may also be subject to a negative externality when a severe windstorm creates a spillover of physical and economic damage. According to our knowledge, the neighborhood effect has not been examined in catastrophe-related contexts using spatial econometric methods. For the case of a catastrophe, the neighborhood effect reflects the spatial dependence (or spatial correlation) among losses in residential market value.

In order to examine spatial dependencies of damages, we utilize the dataset of Oklahoma County residential properties that were damaged in the May 1999 tornado outbreak. On May 3, 1999, a major tornado outbreak consisting of over 60 tornadoes hit the central plains of the U.S. ${ }^{1}$ The state of Oklahoma was hit by several tornadoes and one particularly large tornado that was rated F5 on the Fujita Scale (Fujita 1971) hit south of Oklahoma City. ${ }^{2}$ This tornado, called the Oklahoma City Tornado (OKC) remained on the ground for several hours leaving a damage path that stretched over Grady, McClain, Cleveland, and Oklahoma counties. According to the National Oceanic and Atmospheric Administration, the Oklahoma City tornado killed 40 people and injured another 675. In addition, it caused an estimated $\$ 1$ billion in insured property loss which included thousands of homes and businesses. Figure 1 illustrates the approximate damage paths from the May 3, 1999 tornado outbreak. Storm A in Fig. 1 produced the observations used in our study. The overall Fujita-scale damage ratings for the paths are also shown.

Physical damage documentation has been routinely collected and reported in the wind engineering and atmospheric science literature (e.g., Marshall and Foster 2002; McDonald and Selvam 1990). However, studies of physical damage do not provide a measure useful

\footnotetext{
1 According to the National Oceanic and Atmospheric Administration, this tornado outbreak was the largest ever recorded. In addition, this is the first F5 tornado to hit Oklahoma City MSA.

2 The Fujita (1971) classification system is based on damage caused by a tornado. An F5 is called an "incredible tornado" with estimated wind speeds ranging from 261 to 318 miles per hour. Between 1950 and 1994 less than 1\% of all tornadoes were F4 or F5 intensity. However, the F4 and F5 tornadoes were responsible for $67 \%$ of the tornado related deaths over the same time period (http://lwf.ncdc.noaa. gov/oa/climate/severeweather/tornadoes.html).
} 


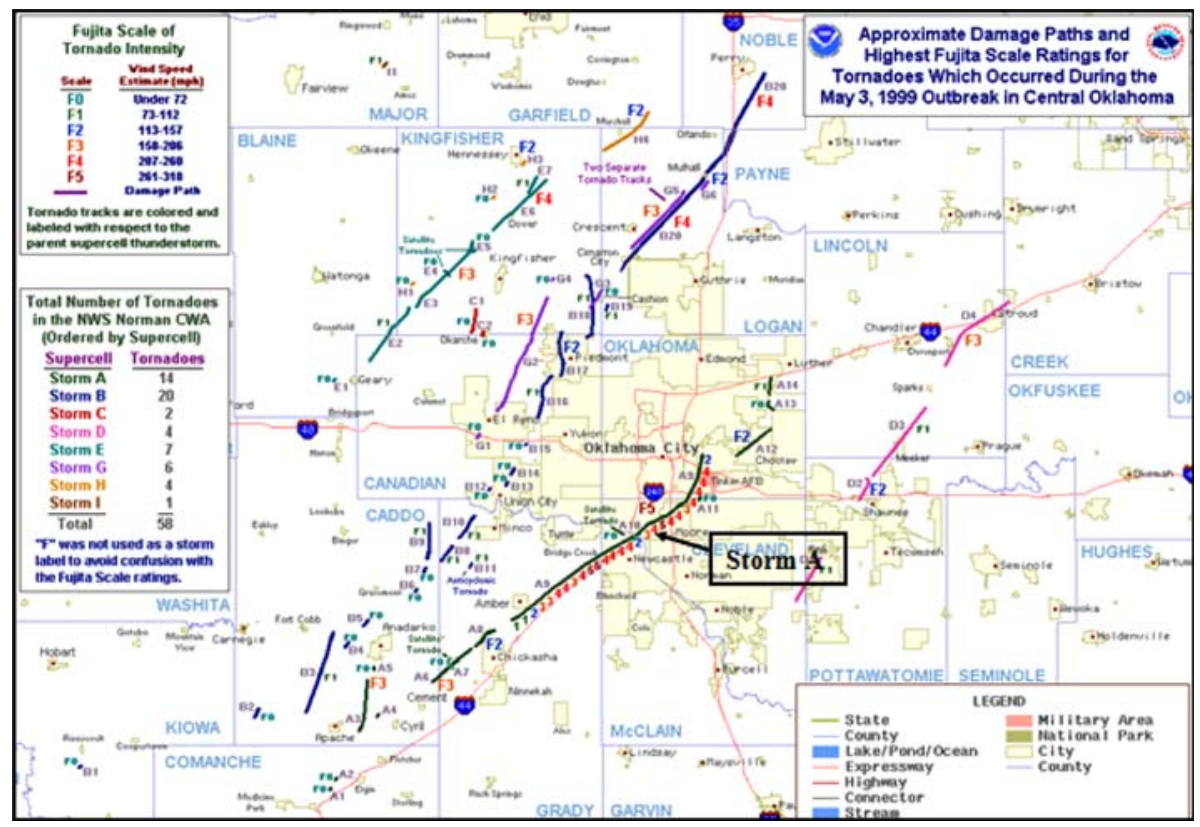

Fig. 1 The May 1999 OKC Tornado damage paths through central Oklahoma. Source: National Weather Service, Norman, OK. Note: Storm A produced the observations used in this study

for comparing losses across hazards or for evaluating damage mitigation investments. Economic measures of losses due to hazards provide such a universal measure. Quantified historical information about tornado intensity and loss from tornado events can help catastrophe aid agencies give appropriate responses. The urgency and importance of such research is emphasized by Meade and Abbott (2003) in the RAND report, "Assessing Federal Research and Development for Hazard Loss Reduction." The authors see the lack of precise economic loss data as a severe limitation to measuring the effectiveness of national hazard loss research and development. This study helps to fill the research gap described by Meade and Abbott (2003) as the missing metric. In this article, we report the results of traditional ordinary least squares (OLS) estimation of residential market value loss due to tornado. We then show that controlling for the spatial dependence of tornado damage produces unbiased estimators compared to OLS.

After including spatial variables in the traditional hedonic analysis of housing damage, we find that losses in market value are consistent with the severity of $F$-scale damage assignments and therefore support civil engineers' expectations and physical observations. The remainder of this article is organized as follows: Sect. 2 discusses related literature, Sect. 3 discusses data sources and descriptive statistics; Sect. 4 gives the empirical analysis, with concluding remarks in Sect. 5.

\section{Literature review}

There are a few catastrophe-related economic studies that deal with after-disaster housing damage estimation. According to our knowledge, this is the first study to model damage 
that tests and incorporates spatial dependencies. The traditional hedonic approach of housing damage studies assumes that the damage to each structure occurs in isolation implying statistical independence. De Silva et al. (2006) studied the after-disaster housing market recovery from the 1999 OKC tornado by comparing damaged and undamaged groups of houses. The focus of the study was to track the recovery process. However, the results also indicated a perverse non-monotonic relationship between $F$-scale damage and dollar losses. Fronstin and Holtmann (1994) use a Tobit model to analyze the determinants of residential property damage caused by hurricane Andrew. They found that the stronger winds generated greater damage to houses, although the results for the lower two wind speed categories were not clear. Some studies that have examined other economic aspects of severe windstorms and mitigation include Merrell et al. 2002a, 2002b; Ewing et al. 2003; Kruse et al. 1999; Simmons and Kruse 2000; Simmons et al. 2002; Kawawaki and Ota 1996; and Cho et al. 2000. None of these studies apply spatial econometric methods nor do they use a micro level dataset similar to ours.

\section{Data}

Fujita (1971) proposed the Fujita-scale or $F$-scale damage rating to measure tornado intensity. This system categorizes tornado intensity into ratings from low to high as light damage $(F-0)$, moderate damage $(F-1)$, considerable damage $(F-2)$, severe damage $(F-3)$, devastating damage $(F-4)$, incredible damage $(F-5)$, and inconceivable damage $(F-6$ or above). Table 1 from Fujita (1971) describes the type of damage and Fujita's estimate of wind speed for each $F$-scale rating. The Fujita Scale is considered the standard for rating tornado damage and is widely used to report the intensity of tornadoes by the National Weather Service, other government authorities, and news media. In fact, tornadoes going back to 1950 have been assigned $F$-scale ratings based on historical accounts of the damage.

The tornado damage measures ( $F$-scale) used in this study are taken from the onsite observation results of the damage survey teams from the Wind Science and Engineering Research Center (WISE) at Texas Tech University (TTU) led by T. Marshall. The 1999 OKC tornado left a damage path 38 miles long and 1,300 feet wide on average in Oklahoma County. Standard practice is to assign a tornado the maximum damage rating observed meaning that if one property sustains $F-3$ damage, the windstorm is rated $F-3$. In contrast the $F$-scale ratings we used were assigned on a per house basis. Since $F$-scale is a subjective rating, it is vulnerable to misclassification, especially by non-engineers, according to Phan and Simiu 1999. Errors could happen when damage ratings to structures do not account for different wind vulnerability zones. Also, misclassification could be the result of an inadequate engineering background for the task, according to Phan and Simiu 1999. Since all the ratings used in our study were performed within the same county by a team of credentialed experienced professional engineers, classification error should be minimized. The TTU damage assessment teams assigned an $F$-scale rating on each structure. This created an opportunity to construct a unique dataset that included reliable individual damage ratings for several hundred damaged properties. The damage assessment teams recorded an $F$-scale damage rating for each surveyed structure on 14 large-scale handdrawn maps. The residential properties along the path are spatially clustered. We use observations on four maps (Map 10 through Map 13) near the Del City and Midwest City areas as the sample. Figure 2 shows the location of maps 10 through 13 relative to the path of the tornado. Figure 3 displays all 762 observations with geographic references (latitude and longitude) with pattern indicators of the $F$-scale damage ratings. The sample includes 
Table 1 Fujita Scale

\begin{tabular}{|c|c|c|c|}
\hline$F$-scale & Damage intensity & Wind speed (mph) & Type of damages \\
\hline$F-0$ & Light damage & $40-72$ & $\begin{array}{l}\text { Some damage to chimneys and TV } \\
\text { antennae; breaks twigs off trees; } \\
\text { pushes over shallow-rooted trees }\end{array}$ \\
\hline$F-1$ & Moderate damage & $73-112$ & $\begin{array}{l}\text { Peels surface off roofs: windows broken; } \\
\text { light trailer houses pushed or } \\
\text { overturned; some trees uprooted or } \\
\text { snapped; moving automobiles pushed } \\
\text { off the road. } 73 \text { mph is the beginning } \\
\text { of hurricane wind speed }\end{array}$ \\
\hline$F-2$ & Considerable damage & $113-157$ & $\begin{array}{l}\text { Roofs torn off frame houses leaving } \\
\text { strong upright walls; weak buildings } \\
\text { in rural areas demolished; trailer } \\
\text { houses destroyed; large trees snapped } \\
\text { or uprooted; railroad boxcars pushed } \\
\text { over; light object missiles generated; } \\
\text { cars blown off highway }\end{array}$ \\
\hline$F-3$ & Severe damage & $158-206$ & $\begin{array}{l}\text { Roofs and some walls torn off frame } \\
\text { houses; some rural buildings } \\
\text { completely demolished; trains } \\
\text { overturned; steel-framed hangar- } \\
\text { warehouse type structures torn; cars } \\
\text { lifted off the ground; most trees in a } \\
\text { forest uprooted; snapped, or leveled }\end{array}$ \\
\hline$F-4$ & Devastating damage & $207-260$ & $\begin{array}{l}\text { Whole frame houses leveled, leaving } \\
\text { piles of debris; steel structures badly } \\
\text { damaged; trees debarked by small } \\
\text { flying debris; cars and trains thrown } \\
\text { some distances or rolled considerable } \\
\text { distances; large missiles generated }\end{array}$ \\
\hline$F-5$ & Incredible damage & $261-318$ & $\begin{array}{l}\text { Whole frame houses tossed off } \\
\text { foundations; steel-reinforced concrete } \\
\text { structures badly damaged; } \\
\text { automobile-sized missiles generated; } \\
\text { incredible phenomena can occur }\end{array}$ \\
\hline$F-6$ or above & Inconceivable damage & 319 Sonic Speed & $\begin{array}{l}\text { Should a tornado with the maximum } \\
\text { wind speed in excess of F6 occur, the } \\
\text { extent and types of damage may not } \\
\text { be conceived. A number of missiles } \\
\text { such as ice boxes, water heaters, } \\
\text { storage tanks, automobiles, etc. will } \\
\text { create serious secondary damage on } \\
\text { structures }\end{array}$ \\
\hline
\end{tabular}

Note: The above information is from Fujita (1971)

249 houses with $F-O$ damage, 83 with $F-1$ damage, 136 with $F-2$ damage, 215 with $F-3$ damage, and finally 79 with an $F-4$ damage rating.

The Oklahoma County Tax Assessor (OKCTA) recorded both the market values of houses and the taxable values of houses. Since there are tax exemptions, for some houses, taxable values are generally smaller than market values. In order to fully reflect housing damage from tornadoes, we use market values to calculate losses. In addition, the OKCTA lists attributes of each property including number of stories, roof type, exterior finish, year 


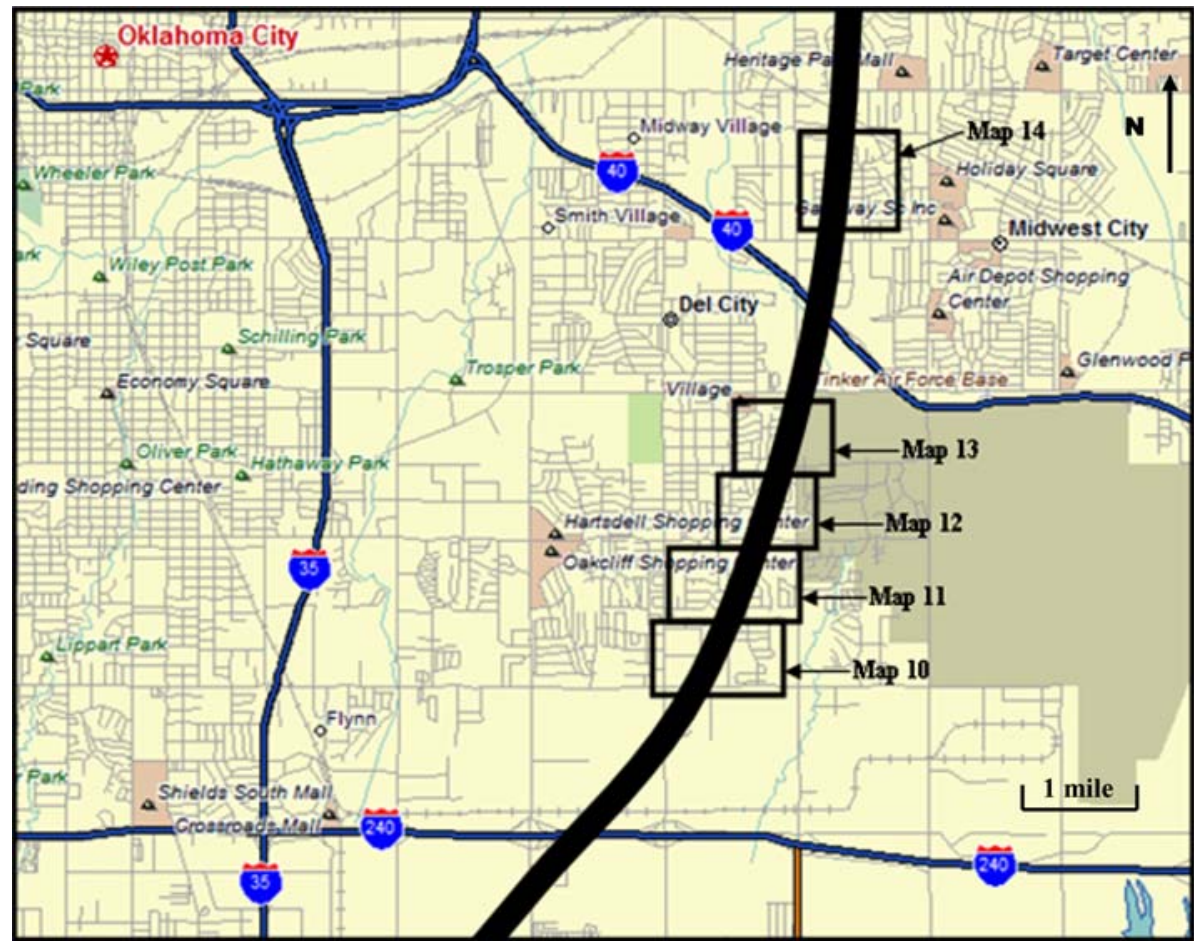

Fig. 2 The May 1999 OKC Tornado damage path through Del City and Midwest City, OK. Note: This map is from 1998 GeoSystems Global Corp-MAPQUEST. The sample data are from Maps 10, 11, 12 and 13

built, building quality, and geographical location. With the help of geographical location, we were able to cross-refer the data from OKCTA with the TTU damage assessment maps.

Table 2 displays the descriptive statistics for the sample. The average house in the sample was 29 years old, had 1412.94 square feet, and lost nearly $\$ 50,000$ in market value as a result of the tornado damage. For each house, the calculated loss is the difference between the pre-tornado market value and the post-tornado market value. The loss ratio is the loss divided by the pre-tornado market value. The ratios vary from 13 to $91.5 \%$ with an average loss ratio of $75 \%$ for the sample.

In addition to the standard damage description of Fujita (1971), Marshall (2002) applied additional damage descriptors (Table 3 ) to refine the $F$-scale rating assignments for the 1999 OKC tornado. An $F-O$ rated house may have a television antenna down, broken windows, damaged garage doors, or a few roof shingles missing. In contrast, $F-4$ damage would find the structure collapsed and only a pile of debris left on the foundation. Figure 4 shows that $F-4$ rated properties lost at least $70 \%$ of their value. We find that lower $F$-scale rated houses show more variation than the ones with higher ratings. The loss ratio of $F-O$ rated houses ranges from about 12 to $90 \%$. One explanation for the high variation of loss ratio at low $F$-scales may be due to neighborhood effects. The onsite observation results of T. Marshall indicated that most debris were broken pieces of wood from houses, furniture, and trees. They became high-speed projectiles in the tornado and penetrated roofs, walls, and windows. 


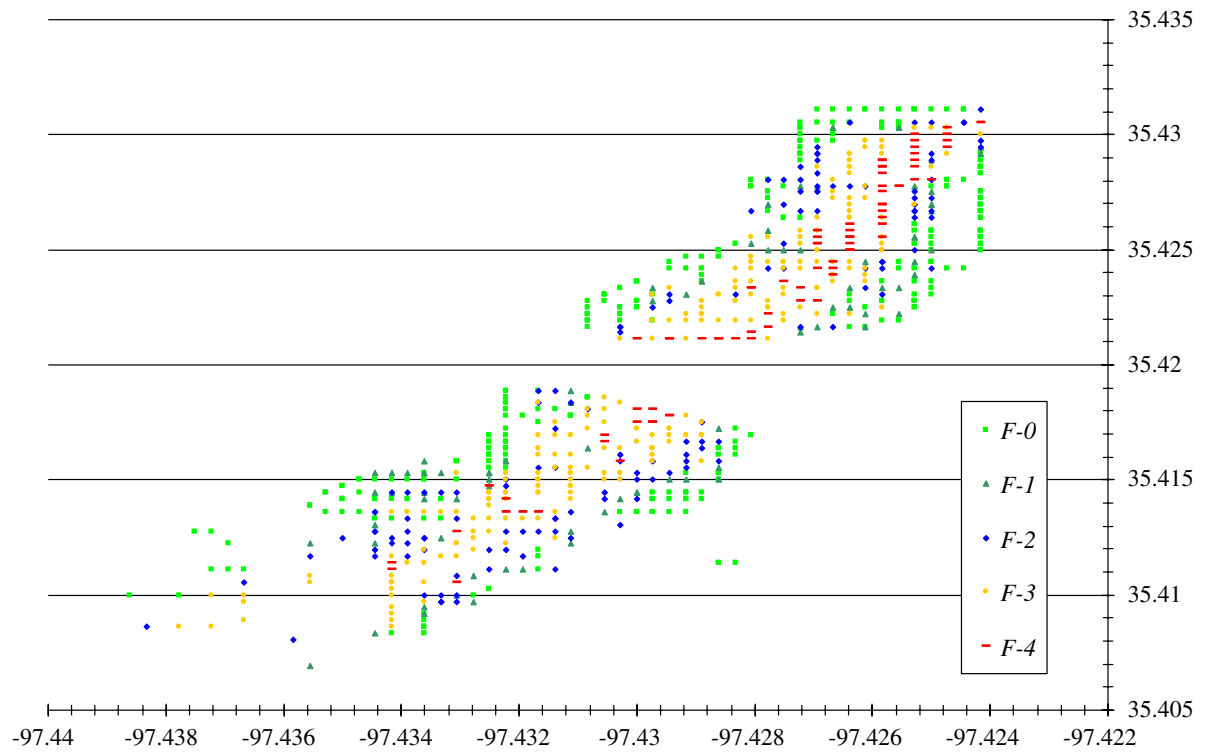

Fig. 3 Geographical locations of damaged residences. Note: There are 762 observations. The vertical axis is latitude, and the horizontal axis is longitude. Each observation is marked by its $F$-scale rating with different patterns: $F-O$ square (light green), $F-1$ triangle (dark green), $F-2$ diamond (blue), $F-3$ star (orange) and $F-4$ short bar (red). Refer also to Table 1 for details

Table 2 Descriptive statistics

Note: Standard deviations are in parentheses

Loss from the 1999

tornado $=$ Market value of 1998 - Market value of 1999

Loss ratio of $1999=$ Loss from the 1999 tornado/Market value of 1998

Building age in $1999=1999-$ Year built

\begin{tabular}{lc}
\hline Variable & Mean \\
\hline $\begin{array}{l}\text { Market value of houses } \\
\text { before tornado }(\$)\end{array}$ & $65229.79(14005.40)$ \\
$\begin{array}{l}\text { Market value of houses } \\
\text { after tornado }(\$)\end{array}$ & $15672.29(11632.61)$ \\
Damage loss from & \\
$\quad$ the 1999 tornado $(\$)$ & $49557.50(17634.78)$ \\
Loss ratio of 1999 & $0.75(0.19)$ \\
Square footage & $1412.94(350.92)$ \\
Building age in 1999 & $28.99(6.34)$ \\
$F$-scale & $1.73(1.43)$ \\
\hline
\end{tabular}

\section{Empirical analysis}

In this section, we analyze housing damage using both the traditional ordinary least squares (OLS) model and the spatial econometric model. The dependent variable is the loss of housing market value $(\text { Loss })^{3}$ measured in U.S. dollars (\$). The explanatory variables are divided into two groups-wind-related variables and housing-related variables. The windrelated variables are $F$-scale dummies including $F-1, F-2, F-3$, and $F-4$ with $F-O$ as the omitted group. They are used to control for the damage intensity of the tornado. The

${ }^{3}$ Loss $=$ House Value in $1998-$ House Value in 1999. 
Table 3 Additional damage descriptions used by T. Marshall when assigning Fujita Scales for the May 1999 Oklahoma City Tornado (adapted from Marshall 2002)

\begin{tabular}{|c|c|}
\hline$F$-scale & Type of damages \\
\hline$F-O$ & $\begin{array}{l}\text { A few roof shingles missing, a downed television antenna, broken windows, } \\
\text { and a damaged garage door }\end{array}$ \\
\hline$F-1$ & $\begin{array}{l}\text { Large areas of the roof covering had been removed. There had been roof decking missing. } \\
\text { The gable end had been blown in or out. The garage door had failed which caused uplift } \\
\text { of the garage roof or collapse of the garage walls }\end{array}$ \\
\hline$F-2$ & Most of the roof structure had been removed but perimeter walls remained intact \\
\hline$F-3$ & $\begin{array}{l}\text { The roof structure and most perimeter walls had been removed, leaving interior } \\
\text { walls standing }\end{array}$ \\
\hline$F-4$ & The house structure had collapsed, leaving a pile of debris on the foundation \\
\hline$F-5$ & $\begin{array}{l}\text { The majority of the house structure and contents had been displaced downwind from } \\
\text { the foundation }\end{array}$ \\
\hline
\end{tabular}

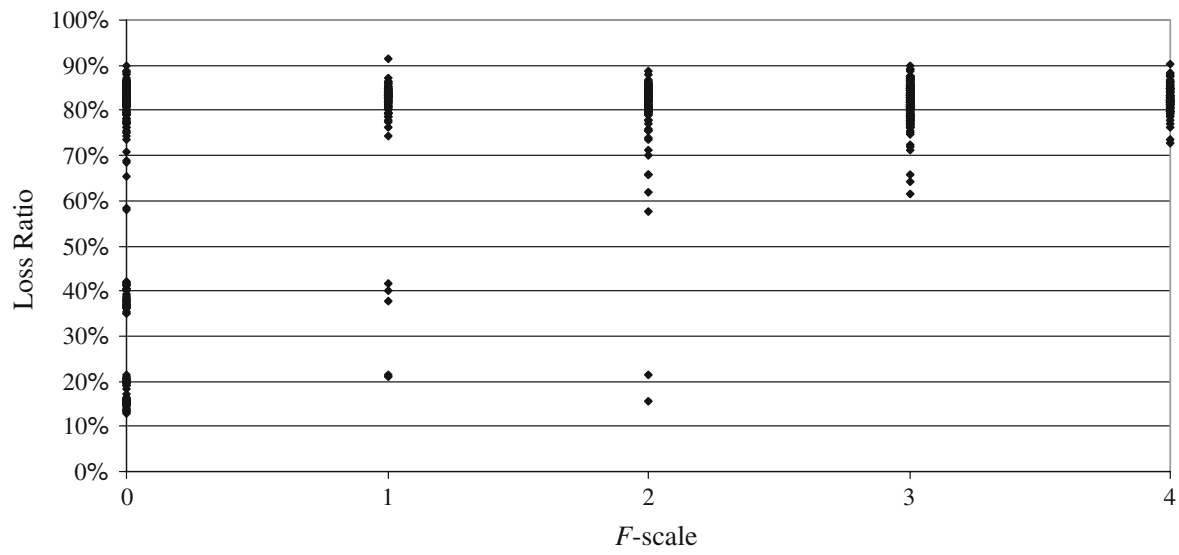

Fig. 4 Tornado dollar loss ratios and corresponding $F$-scales

housing-related variables include variables such as "square footage," "stories," "building age" ; and housing-related dummy variables that are presented in three groups to capture structural features. "Hip roof" and "gable roof" are two dummy variables to control for roof type with the third category, "hip and gable roof" left as the omitted group. Besides roof type, we also control for structural features such as foundation type and exterior finish. From the sample, we construct one foundation dummy, "slab foundation" and use "conventional foundation" as the omitted group. There are seven different types of exteriors in the sample. With the omitted group of "frame hardboard/stucco," we construct six exterior dummies including "frame masonry veneer exterior," "frame vinyl exterior," "frame permastone exterior," "frame siding exterior," "frame asbestos exterior," and "frame comp shingle exterior." OKCTA assigns building quality levels from low, fair, fair plus, average, good, very good, to excellent. According to the quality levels in the sample, we create dummy variables, "Building quality (fair plus)" and "Building quality

\footnotetext{
${ }^{4}$ Building Age $=1999-$ Year Built.
} 
Table 4 Summary statistics of regression variables. Standard deviations are in parentheses

\begin{tabular}{lc}
\hline Variable & Mean \\
\hline Loss & $49557.50(17634.78)$ \\
Log (Loss) & $10.70(0.54)$ \\
$F-1$ & $0.11(0.31)$ \\
$F-2$ & $0.18(0.38)$ \\
$F-3$ & $0.28(0.45)$ \\
$F-4$ & $0.10(0.31)$ \\
Square footage & $1412.94(350.92)$ \\
Log (Square footage) & $7.22(0.24)$ \\
Stories & $1.06(0.22)$ \\
Hip roof & $0.31(0.46)$ \\
Gable roof & $0.55(0.50)$ \\
Slab foundation & $0.97(0.16)$ \\
Frame masonry veneer exterior & $0.98(0.15)$ \\
Frame vinyl exterior & $0.01(0.09)$ \\
Frame permastone exterior & $0.004(0.06)$ \\
Frame siding exterior & $0.003(0.05)$ \\
Frame asbestos exterior & $0.003(0.05)$ \\
Frame comp shingle exterior & $0.003(0.05)$ \\
Building quality (Fair plus) & $0.17(0.37)$ \\
Building quality (Average) & $0.27(0.45)$ \\
Building age & $28.99(6.34)$ \\
Log (Building age) & $3.34(0.22)$ \\
\hline
\end{tabular}

(average)." The omitted group is the poorest quality level, "fair." Table 4 shows a complete list of variables and their summary statistics.

As discussed earlier, neighborhood effects may lead to spillover losses in addition to direct wind damage caused by the tornado. These relationships can be identified as spatial dependencies (or spatial autocorrelation), which means one observation in one location depends on another observation in a different location. ${ }^{5}$ Anselin and Bera (1998) loosely defined spatial dependence as the coincidence of value similarity with locational similarity. Mathematically, it is expressed as:

$$
\operatorname{Cov}\left(y_{i} y_{j}\right)=E\left(y_{i} y_{j}\right)-E\left(y_{i}\right) \cdot E\left(y_{j}\right) \neq 0 \quad \text { for } i \neq j
$$

where, $y$ is a random variable.

In the case of tornado damage, it means that the loss sustained by one residence may affect or be affected by the destruction of neighboring structures. Spatial dependence can occur among the dependent variables (spatial lagged dependence), among error terms (spatial error dependence), or be the general case where you observe both of the above. Ignoring spatial correlation may result in the OLS estimators that are biased, inconsistent, or inefficient.

According to Anselin (1988) and LeSage (1999), three spatial econometric models can be used to deal with this problem. First, the general spatial model (GSM) is used to deal

\footnotetext{
5 See Anselin (1988) and LeSage (1999) for more details on spatial correlations.
} 
with both types of spatial dependence (spatial lagged dependence and spatial error dependence). The model is as follows:

$$
\begin{aligned}
& Y=\rho W_{1} Y+X \beta+\mu \\
& \mu=\lambda W_{2} \mu+\varepsilon \\
& \varepsilon \sim N\left(0, \sigma^{2} I_{n}\right)
\end{aligned}
$$

where, $W_{1} Y$ is the spatial lagged term; and $W_{2} \mu$ is the spatial error term. $W_{1}$ and $W_{2}$ are $n \times n$ spatial weight matrices to identify the geographical relationship among observations using geo-coordinate information. $Y$ is an $n \times 1$ vector of dependent variables; and $X$ is an $n \times k$ matrix of explanatory variables. Both $\mu$ and $\varepsilon$ are $n \times 1$ vectors of error terms. $\mu$ is the vector of spatially correlated error terms; and $\varepsilon$ is the vector of uncorrelated error terms. $\rho, \beta$, and $\lambda$ are vectors of coefficients. Some spatially correlated datasets may have only spatial dependence among the dependent variables while some may have only spatial dependence among the error terms. In these cases, GSM is simplified into two other models: mixed autoregressive model (SAR) and spatial error model (SEM). When there is only spatial lagged dependence in the model $\left(W_{2}=0\right)$ and all other variables are the same as GSM, the SAR is used,

$$
\begin{aligned}
& y=\rho W_{1} y+X \beta+\varepsilon \\
& \varepsilon \sim N\left(0, \sigma^{2} I_{n}\right)
\end{aligned}
$$

When there is only spatial error dependence in the model $\left(W_{1}=0\right)$ and all other variables are the same as GSM, the SEM is appropriate. ${ }^{6}$

$$
\begin{aligned}
& y=X \beta+\mu \\
& \mu=\lambda W_{2} \mu+\varepsilon \\
& \varepsilon \sim N\left(0, \sigma^{2} I_{n}\right)
\end{aligned}
$$

The Lagrange multiplier (LM) test is used to detect the type of spatial dependence in the data. The null hypothesis of the LM test is that there is no spatial dependence in the residuals. We tested for spatial dependence following the procedures discussed in LeSage (1999). Table 5 shows the test results for the sample. First, we test the OLS model to find the correlation among OLS error terms to determine if the SEM model is appropriate. Second, we test the residuals from the SAR model to determine whether the inclusion of the spatial lag term eliminates spatial dependence in the residuals of OLS model. The null hypothesis of the LM test is that there is no spatial lagged dependence and spatial error dependence in the OLS model. LM test results failed to reject the null hypothesis. The GSM model is the appropriate choice when both types of spatial dependence occur. With the evidence of spatial dependence in the sample observations and the model specification errors discussed in Greene (1997), the OLS model falls into the specification error of omission of relevant variables. Without including spatial variables in the model, the results of OLS are biased.

${ }^{6}$ See Anselin (1988) and LeSage (1999) for detailed discussion about spatial models. 
Table 5 Spatial dependence test statistics. Probabilities are in the parentheses

\begin{tabular}{lll}
\hline Model & $\begin{array}{l}\text { LM value } \\
\text { (Level regression) }\end{array}$ & $\begin{array}{l}\text { LM value } \\
\text { (Log regression) }\end{array}$ \\
\hline Spatial Error Model & $73.319(0.000)$ & $95.994(0.000)$ \\
Mixed Autoregressive Model & $78.690(0.000)$ & $96.228(0.000)$ \\
\hline
\end{tabular}

Table 6 Regression results for loss

\begin{tabular}{|c|c|c|}
\hline Variable & Spatially Unadjusted Model & Spatially Adjusted Model \\
\hline Constant & $-15437.34(9246.13)$ & $-16489.57(9294.18)$ \\
\hline$F-1$ & $9683.53 * *(1379.87)$ & $7824.64 * *(1277.70)$ \\
\hline$F-2$ & $10881.43^{* *}(1180.38)$ & $9321.62 * *(1140.26)$ \\
\hline$F-3$ & $10341.72 * *(1019.03)$ & $9684.25 * *(1052.29)$ \\
\hline$F-4$ & $13498.63 * *(1398.26)$ & $12829.01 * *(1415.38)$ \\
\hline Square footage & $27.38 * *(1.62)$ & $26.85 * *(1.57)$ \\
\hline Stories & $-5083.68 * *(2048.90)$ & $-4777.30 * *(1915.52)$ \\
\hline Hip roof & $-48.98(1331.26)$ & $670.00(1187.49)$ \\
\hline Gable roof & $-850.73(1194.70)$ & $-405.04(1059.21)$ \\
\hline Slab foundation & $5420.16(4587.77)$ & $5406.98(4914.19)$ \\
\hline Frame masonry veneer exterior & $28375.75 * *(8990.62)$ & $29009.26 * *(9531.66)$ \\
\hline Frame vinyl exterior & $23396.89 * *(8973.04)$ & $27209.33 * *(8626.77)$ \\
\hline Frame permastone exterior & 9794.53 (9944.69) & $15090.82(8969.27)$ \\
\hline Frame siding exterior & $24604.03 * *(10864.03)$ & $29984.99 * *(10588.44)$ \\
\hline Frame asbestos exterior & $23896.55^{* *}(10889.86)$ & $26791.06 * *(10990.86)$ \\
\hline Frame comp shingle exterior & $19604.01(11048.97)$ & $28437.03 * *(10861.55)$ \\
\hline Building quality (Fair plus) & $5153.17 * *(1279.62)$ & $5623.00 * *(1262.01)$ \\
\hline Building quality (Average) & $4687.01 * *(1496.70)$ & $5431.50 * *(1523.84)$ \\
\hline Building age & $-369.42 * *(109.60)$ & $-361.00 * *(111.70)$ \\
\hline$\rho$ & & $0.01^{*}(0.01)$ \\
\hline$\lambda$ & & $0.27 * *(0.03)$ \\
\hline Adjusted $R^{2}$ & 0.63 & 0.69 \\
\hline Log likelihood & & -7401.16 \\
\hline Number of observation & 762 & 762 \\
\hline
\end{tabular}

Note: Standard deviations are in parentheses. $* *$ Denotes $5 \%$ significance and $*$ denotes $10 \%$ significance

Table 6 shows the results for spatially unadjusted OLS and spatially adjusted GSM regressions. The first column lists the names of variables. The second column displays the results of OLS, which provide a reference point for comparison with the results of GSM shown in the third column.

In the OLS results, the coefficient of $F-2$ (10881.43) is larger than that of $F-3$ (10341.72). This implies the counterintuitive result that houses with less physical damage experience greater losses in market value. We believe that these inconsistencies are due to biased OLS results.

The results of GSM indicate that relative to $F-O$ damage, $F-1, F-2, F-3$, and $F-4$ damages are associated with market value losses that increase accordingly with the damage rank. There is a positive monotonic relationship between physical damage ratings and lost 
market value of property. In Table 6 , the results show that $\lambda$, the coefficient of spatial error term, is statistically significant and $\rho$, the coefficient of spatial lagged term, is marginally significant at $10 \%$. However, note that LM test results in Table 5 indicate that spatial error and lagged terms matter. The results of spatial variables indicate that housing value losses among neighboring residences are correlated. Both $\rho$ and $\lambda$ are decaying numbers, which means that the greater the distance between houses, the less impact they make on each other. $\rho$ gauges how tornado losses of neighboring residences affect each other directly, such as debris strikes. $\lambda$ measures how the value loss of a house is affected by a shock to the losses of neighboring houses. In this case, the shock is the intensity of the tornado that struck a neighboring house. The higher the intensity of a tornado striking a structure, the more the debris will likely be produced from it. This increases the potential threat to surrounding houses. $\rho$ and $\lambda$ together quantify the magnitude of neighborhood effect resulted from tornado strike and collateral damage.

Further, the results of the GSM model indicate that larger houses are at the risk of higher losses, which is not surprising. Housing damage increases by $\$ 26.85$ per square foot. Multi-story houses regularly have higher market values and are larger than single story homes. However, the results show that a house with two stories has lower value losses by nearly $\$ 5,000$ per story. This may be due to the protection to the ground floor that an uper story provides. As for roof dummy variables, the results are different from our expectations. According to the American Society of Civil Engineers (ASCE) Standard 7-02, a hip roof can deflect the wind better than a gable roof, and is less vulnerable to wind damage. However, the results show that relative to a hip-and-gable roof, a house sustains $\$ 670$ greater loss when it has a hip-only roof; and $\$ 405$ smaller loss when it has a gable-only roof. A house with a slab foundation sustains a higher loss when compared to a house built on a conventional foundation. Relative to the omitted frame hardboard/stucco exterior, houses with all the other six exteriors sustain more damage. The Building quality variable provide some interesting results. We find that relative to houses rated in "fair" condition, "fair plus" and "average" condition houses sustain higher losses. Between the two higher quality ratings, a house of average quality has nearly \$200 less damage than a house of fair plus quality. A possible explanation of these results would relate to the method used to assign the quality rating. Houses that have similar structural integrity can receive different quality scores if one has been recently painted and the other not. Houses with a "fair" quality rating would be given a lower estimated market value implying that in the case of a windstorm there is less to lose. ${ }^{7}$ Finally, we find that newer homes incur higher losses after controlling for all other factors. A house that is one year newer sustains $\$ 360$ more damage than a similar older house. These results are similar to those found by Fronstin and Holtmann (1994) who attributed higher losses to erosion of construction quality and lax enforcement of building codes.

Next, we estimate our empirical model as a log linear function, more inline with traditional hedonic studies. Again, the LM test results for log regressions in Table 5 indicate that GSM is the appropriate specification for our empirical model. The regression results are given in Table 7 . The results indicate that in the spatially unadjusted model, we do not observe a monotonic relationship between $F$-scales and losses. When we account for spatial dependencies, our results show the monotonic relationship between $F$-scales and losses.

\footnotetext{
7 The results of a spatial regression (GSM) using the loss ratio as the dependent variable yields weaker but similar results so that the "less to lose" argument does not fully explain the relationship.
} 
Table 7 Regression results for log value of loss

\begin{tabular}{lcc}
\hline Variable & Spatially Unadjusted Model & Spatially Adjusted Model \\
\hline Constant & $3.88^{* *}(0.88)$ & $3.85^{* *}(0.68)$ \\
$F-1$ & $0.39^{* *}(0.05)$ & $0.30^{* *}(0.04)$ \\
$F-2$ & $0.41^{* *}(0.04)$ & $0.34^{* *}(0.04)$ \\
$F-3$ & $0.39^{* *}(0.04)$ & $0.36^{* *}(0.04)$ \\
$F-4$ & $0.48^{* *}(0.04)$ & $0.45^{* *}(0.05)$ \\
Log (Square footage) & $0.82^{* *}(0.09)$ & $0.78^{* *}(0.06)$ \\
Stories & $-0.13(0.08)$ & $-0.11(0.06)$ \\
Hip roof & $-0.01(0.05)$ & $0.01(0.04)$ \\
Gable roof & $-0.00(0.05)$ & $0.01(0.04)$ \\
Slab foundation & $0.21(0.12)$ & $0.23(0.15)$ \\
Frame masonry veneer exterior & $1.14 * *(0.44)$ & $1.11^{* *}(0.28)$ \\
Frame vinyl exterior & $0.40(0.49)$ & $0.54(0.28)$ \\
Frame permastone exterior & $0.63(0.43)$ & $0.83 * *(0.29)$ \\
Frame siding exterior & $0.70(0.44)$ & $0.90 * *(0.34)$ \\
Frame asbestos exterior & $0.81(0.43)$ & $0.72(0.37)$ \\
Frame comp shingle exterior & $0.63(0.44)$ & $0.83(0.34)$ \\
Building quality (Fair plus) & $0.19^{* *}(0.04)$ & $0.20^{* *}(0.04)$ \\
Building quality (Average) & $0.16^{* *}(0.06)$ & $0.20^{* *}(0.04)$ \\
Log (Building age) & $-0.18(0.14)$ & $-0.12(0.07)$ \\
$\rho$ & & $0.004(0.003)$ \\
$\lambda$ & & $0.31 * *(0.02)$ \\
Adjusted $R^{2}$ & 0.49 & 0.59 \\
Log likelihood & 762 & 406.35 \\
Number of observation & & 762 \\
\hline$N o t e$ Stand & &
\end{tabular}

Note: Standard deviations are in parentheses. $* *$ Denotes $5 \%$ significance and $*$ denotes $10 \%$ significance

\section{Conclusion}

This project examines the spatial dependence among housing damage caused by tornadoes using data from the May 1999 OKC tornado. We find that housing damage in this tornado disaster area is highly correlated. Besides strikes from tornadoes, monetary losses are aggravated by the damage to nearby houses and the debris of damaged houses around them. It is an example of a negative spillover. In comparison to the OLS model, the GSM model provides unbiased estimates by considering both spatial lagged dependence and spatial error dependence. Application of spatial econometric modeling results in more accurate economic loss estimation. The results of this study provide information useful for insurance underwriters, home builders, and public officials interested in wind damage mitigation. Further, the spatial econometric model provides a more complete picture of the geographic variation in damage from a tornado. This information is useful to insurance companies in describing their book of business and therefore describing their distribution of risk. In order to construct appropriate home insurance policies for tornado disasters or to improve the damage resistance capabilities of houses, it is necessary for insurance underwriters and builders to consider spatial correlation of tornado damage. 
Acknowledgment This work was performed under the Department of Commerce NIST/TTU Cooperative Agreement Award 70NANB8H0059. We would like to thank Dr. Douglas A. Smith, and the participants at both the 2005 Western Economic Association International meeting (San Francisco, CA) and the 2004 Southern Economics Association meeting (New Orleans, LA) for useful comments and suggestions.

\section{References}

Anselin L (1988) Spatial econometrics: methods and models. Kluwer Academic Publishers, Dordrecht

Anselin L, Bera AK (1998) Spatial dependence in linear regression models with an introduction to spatial econometrics. In: Ullah A, Giles DEA (eds) Handbook of applied economic statistics. Marcel Dekker, New York

ASCE Standard-Minimum Design Loads for Buildings and Other Structures (2002) American Society of Civil Engineers

Cho S, Gordon P, Richardson HR, Moore JE II, Shinozuka M (2000) Analyzing transportation reconstruction network strategies: a full cost approach. Rev Urban Region Dev Stud 12(3):212-227

De Silva DG, Kruse JB, Wang Y (2006) Catastrophe-induced destruction and reconstruction. Nat Hazards Rev 7(1):19-25

Ewing BT, Kruse JB, Thompson MA (2003) Labor market responses to tornadoes. In: Proceedings of the 11th international conference on wind engineering, Lubbock, TX

Fronstin P, Holtmann AG (1994) The determinants of residential property damage caused by hurricane Andrew. South Econ J 61(2):387-397

Fujita TT (1971) A proposed characterization of tornadoes and hurricanes by area and intensity. SMRP Paper 91(42), University of Chicago

Golden JH, Snow JT (1991) Mitigation against extreme windstorms. Rev Geophys 29(4):477-504

Greene WH (1997) Econometric analysis, 3rd edn. Prentice Hall, Englewood Cliffs, NJ

Kawawaki Y, Ota M (1996) The influence of the great Hanshin-Awaji earthquake on the local housing market. Rev Urban Region Dev Stud 8:220-233

Kruse JB, Simmons K, Tiglioglu T (1999) Nashville tornado-economic damage estimation using tax assessor and insurance data. In: Larsen A, Larose GL, Livesey FM (eds) Wind engineering into the 21st century. Brookfield Publication, A. A. Balkema/Rotterdam

LeSage JP (1999) Spatial econometrics. http://www.spatial-econometrics.com (Data retrieved in May 2003)

Marshall TP (2002) Damage survey at Moore, Oklahoma Tornado. Weather Forecast 17(3):582-598

Marshall TP, Foster M (2002) Damage survey and radar analysis of the Forth Worth and Arlington, TX tornadoes on 28 March 2000. In: Proceedings 21st conference on severe local storms, San Antonio, TX

McDonald JR, Selvam P (1990) The West Memphis, Arkansas tornado of December 14, 1987. J Wind Eng Ind Aerodynam 6:279-287

Meade C, Abbott M (2003) Assessing federal research and development for hazard loss reduction. Prepared for the White House Office of Science Technology and Policy, RAND, Santa Monica, CA

Merrell D, Simmons KM, Sutter D (2002a) The market for tornado safety: analysis of applications to the Oklahoma saferoom initiative. J Econ 28(1):35-50

Merrell D, Simmons KM, Sutter D (2002b) Taking shelter: estimating the safety benefits of tornado safe rooms. Weather Forecast 17:619-625

O’Sullivan A (2003) Urban economics. McGraw-Hill Higher Education, Boston

Phan LT, Simiu E (1999) The Fujita Intensity Scale: a reassessment from structural engineering perspective. Proceedings of 31st joint meetings wind and seismic effects. US/Japan Natural Resources Development Program, Tsukuba, Japan, pp 469-474

Simmons KM, Kruse JB (2000) Market value of mitigation and perceived risk: empirical results. J Econ 26(1):41-51

Simmons KM, Kruse JB, Smith D (2002) Valuing mitigation: real estate market response to Hurricane loss reduction measures. South Econ J 68(3):660-671 